\title{
A TRAJETÓRIA DA EDUCAÇÃo A DISTÂNCIA NA PUCPR: revendo o passado, vivendo o presente, visionando o futuro
}

\section{The distance education trajectory at PUCPR: revealing the past, living the present, visioning the future}

Camile Gonçalves Hesketh ${ }^{1}$

Paulo Roberto Alcântara ${ }^{2}$

Patrícia Lupion Torres ${ }^{3}$

\section{Resumo}

Neste artigo, descrevemos alguns dos principais caminhos trilhados pela Educação a Distância na PUCPR. Uma visão histórica é o nosso pano de fundo para tecermos algumas considerações sobre os acontecimentos presentes e projetos futuros. Partindo das primeiras experiências realizadas, comparamos alguns modelos de Educação a Distância adotados pela instituição, como uma forma de compreendermos a trajetória de uma universidade que pretende tornarse um pólo relevante de Educação a Distância. Uma revisão dessa caminhada torna-se fundamental para redirecionarmos nossos esforços ao futuro desejado. Palavras-chave: Educação a distância; Interação; Ambiente virtual de aprendizagem (AVA); Aprendizagem em redes; Colaboração.

\footnotetext{
Mestranda em Educação pela Pontifícia Universidade Católica do Paraná, Especialista em Leitura de Múltiplas Linguagens pela mesma instituição, pedagoga integrante da equipe da Coordenadoria de Educação a Distância da PUCPR.

E-mail: camihesk@uol.com.br

2 Ph.D. em Educação e Desenvolvimento Humano e Mestre em Educação pelo George Peabody College of Vanderbilt University, professor do Programa de Mestrado em Educação da PUCPR, coordenador da Linha de Pesquisa Educação, Comunicação e Tecnologia e professor da Graduação em Pedagogia da PUCPR. Rua Imaculada Conceição, 1155, Prado Velho, Curitiba - PR, CEP 80.215-901.

E-mail: paulo.alcantara@pucpr.br

3 Doutora em Engenharia de Produção - Mídia e Conhecimento pela Universidade Federal de Santa Catarina, professora do Programa de Mestrado em Educação da PUCPR, Diretora da Área de Educação da PUCPR e professora da Graduação em Pedagogia da PUCPR. Rua Imaculada Conceição, 1155, Prado Velho, Curitiba - PR, CEP 80.215-901.

E-mail: patorres@terra.com.br
} 


\section{Abstract}

In this article we describe some of the main paths trailed by the Distance Education at PUCPR. A historical view is our background to weave some considerations about the present accomplishments and the future projects. Departing from the first accomplished experiences, we compared some Distance Education's models adopted by the institution, as a form of comprehending the trajectory of a university that intends to become a relevant setting of Distance Education. A revision of this walk becomes fundamental to redirect our efforts to the wished future.

Keywords: Distance education; Interaction; Virtual learning environment (VLE); Network learning; Collaboration.

\section{Introdução}

"O espaço éfuturo imediato epassa do imediato, um presenteao mesmo tempo concluído e incluso, num processo sempre renovado" (SANTOS, 1997, p. 7).

Produzir um texto sobre a experiência de Educação a Distância (EaD) de uma instituição como a Pontifícia Universidade Católica do Paraná é algo desafiador, principalmente se pensarmos que após muitos percalços, a EaD passou a ocupar um dos principais objetivos estratégicos da instituição (Plano Estratégico PUCPR, 2002, p. 9). Assim, notamos que quando revisitamos o seu passado, elucidamos o seu presente, e conseqüentemente compreendemos melhor os seus projetos futuros. Partindo deste princípio, o futuro da EaD da PUCPR será proveniente das escolhas que estão sendo feitas no presente, assim como o hoje é o resultado de algumas opções realizadas no passado. Como nos diz Santos (2000):

A história pode ser vista como um fluxo ininterrupto, onde passado e futuro se entrelaçam num presente mais ou menos revelador dos processos responsáveis pelas grandes mudanças. Estas nem sempre são percebidas, porque têm suas origens em movimentos de fundo, acelerações até então desconhecidas e com a entrada em cena de novos atores (p. 29).

\section{Em algum lugar do passado}

"O passado nunca conhece o seu lugar. O passado está sempre presente". (QUINTANA, 1983, p. 22)

A trajetória de Educação a Distância da PUCPR iniciou em fevereiro de 1997, com a criação do Laboratório de Mídias Interativas - LAMI, fruto de 
uma parceria com a SIEMENS Telecomunicações. Naquela época, devido aos avanços da informática, as empresas brasileiras haviam descoberto a força da multimídia e principalmente do CD-ROM. O resultado inicial dessa parceria deu origem à produção de um conjunto de conteúdos em CD-ROM na área de telecomunicações, baseados nos CBTs (Computer Based Training), os quais faziam parte de um programa de treinamento para os funcionários da empresa. Simão Neto (2002) em seu artigo sobre os diferentes modelos de Educação a Distância existentes, enfatiza que:

(...) o CBT, como o nome já sugere, trata-se de treinamento - que não é o mesmo que educação. Treinamento envolve objetivos procedimentais, desenvolvimento de habilidades, pensamento operacional, estratégias imitativas (reprodutivas). Educação é um processo contínuo e complexo, no qual não só o pensamento operativo é mobilizado, mas também o lógico e o racional, além do sensível e emocional, com finalidades de formação integral (p. 58).

Considerando que a necessidade inicial da SIEMENS era a aquisição de novas habilidades e procedimentos por parte de seus funcionários, podemos dizer que os CBTs produzidos na época, mesmo não priorizando a questão da interatividade e da não linearidade, características fundamentais dos materiais multimídia, cumpriram o objetivo inicial desejado, na medida em que permitiam que os usuários tivessem acesso a um grande repositório de informações digitalizadas.

No entanto, percebemos pela própria metáfora das páginas viradas na tela que os materiais produzidos em CBTs ainda estavam atrelados à mesma lógica linear dos meios impressos. De acordo com Primo (1997), o diferencial preponderante dos CD-ROMs multimídia é a sua não linearidade, e comenta que:

Um programa de TV ou um livro de ficção tem suas mensagens recebidas de forma linear. Isto é, tem um começo, um meio e um fim, cada parte depende da anterior. (...) Não se deve supor que qualquer intervenção do usuário em um título dito "interativo", represente possibilidade de escolha ou capacidade não linear do produto. Muitos títulos em CD-ROM apresentam telas que permanecem estampadas no monitor até que o usuário clique sobre um botão intitulado "avança". Isso não constitui não linearidade, mas sim um fluxo linear interrompido (p. 94).

Ainda com relação aos CBTs produzidos, podemos observar que havia um descompasso entre os aspectos técnicos, pedagógicos e comunicativos, o que revelaria mais tarde a necessidade da formação de uma equipe multidisciplinar. 
Simão Neto (2002) ressalta também em seu artigo:

o problema é quando o CBT é utilizado como a forma preferencial para programas de educação à distância. Isto leva a uma redução do conceito e do alcance da educação ao processo de treinamento, reforçando os paradigmas tradicionais e conservadores (p. 58).

Se pensarmos que as informações contidas nos CBTs ficavam obsoletas muito rapidamente, já que não podiam ser atualizadas à medida que o conteúdo se alterava, foi preciso dar um passo além. A partir de 1998, um novo projeto com a SIEMENS foi firmado para a concepção de WBTs (treinamento baseado na WEB), o que ampliou a equipe do LAMI, permitindo o desenvolvimento de novos produtos educacionais.

Segundo Lucena (1999):

O maior propulsor do treinamento baseado na web é a necessidade de encontrar maneiras de trazer o treinamento diretamente para o desktop de uma forma just-in-time, treinamento de uma pessoa que requer uma nova habilidade ou conhecimento, no momento em que essa habilidade ou conhecimento se torna necessário.

Para Simão Neto (2002), a Internet tornou-se um meio mais ágil e mais rápido para distribuição de cursos nesse formato. Ainda segundo o autor, o web-based training (WBT) é a versão on-line do CBT. A mudança acontece somente no canal de entrega, o qual passa a ser a web, pois a abordagem continua centrada na transmissão de conteúdos e não na aprendizagem.

Assim, observamos que na transição dos CBTs para os WBTs, mudavam-se os meios, mas a lógica permanecia a mesma. Ou seja, o fato das informações passarem a ser estruturadas em hiperdocumentos, e poderem ser acessadas via Web, não ocasionava mudanças significativas, pois a proposta pedagógica ainda considerava o aluno como um ser passivo, portanto, continuava sendo baseada na transmissão de conteúdos.

Para Macluhan (1996), a linguagem de um novo canal traz consigo características do canal (ou canais) que o antecedem. Assim como a linguagem do cinema se desenvolveu a partir da fotografia e do teatro e a linguagem da televisão teve que adaptar-se a uma série de técnicas desenvolvidas para o cinema, a multimídia precisaria também encontrar uma linguagem própria, se não nova, reformulada e repensada, capaz de fornecer aos alunos muito mais do que conteúdo informativo.

Durante a experiência com os WBTs, verificou-se que a sua produção demandava uma equipe numerosa e que o trabalho realizado era grande demais, considerando o real aproveitamento das páginas meramente informa- 
tivas para a aprendizagem dos alunos. Sendo assim, tornou-se fundamental para uma evolução natural dar mais um passo além. Foi a partir de então que a preocupação com a interação passou a fazer parte da história da Educação a Distância da PUCPR.

Partindo da etimologia da palavra interação, (inter + ação = ação entre) como propõe Primo e Moraes (1999), percebemos que ambos tratam o conceito como uma "ação entre entes". Segundo Moraes, quando falamos em interação, "(...) há de se pressupor que está presente uma relação entre, no mínimo dois agentes; uma ação mútua".

$\mathrm{Na}$ área da Educação, mais especificamente no campo da Educação a Distância (EAD), as interações se fazem primordiais para um aprendizado efetivo, pois é por meio delas que podemos analisar e avaliar o processo de ensino e aprendizagem.

De acordo com Carneiro (2000), "(...) a interação social está presente no processo de aprendizagem, pois denota a importância da relação entre indivíduo e ambiente na construção de processos psicológicos" (p. 35).

Pensando na importância da interação para a aprendizagem dos alunos, verificou-se que a utilização de um ambiente virtual poderia suprir boa parte das dificuldades encontradas. No entanto, havia duas opções: a PUCPR utilizaria algum dos ambientes já existentes na época ou desenvolveria o seu próprio ambiente.

Após várias discussões, foi decidido que era preferível ter uma equipe própria capaz de desenvolver um ambiente virtual que tivesse ferramentas capazes de propiciar novas formas de comunicação entre professores e alunos, atendendo as especificidades da instituição. Foi então que em julho de 1998, a parceria entre a PUCPR e a SIEMENS Telecomunicações foi estendida com o objetivo de desenvolver tal ambiente virtual de aprendizagem. Deste projeto, nasceu o Eureka, um ambiente criado inicialmente para atender as especificidades da SIEMENS e o qual mais tarde passaria a ser utilizado institucionalmente na PUCPR.

Segundo Pernias (2002):

Se você tiver uma equipe de informática interessada, com alguns técnicos e bolsistas capacitados, que entendam como funciona a gestão da universidade, seu projeto educacional e o potencial da tecnologia, vale a pena investir no desenvolvimento de um ambiente próprio. No que diz respeito aos ambientes já existentes, como WebCT ou Blackboard, eu diria que são muito caros e não permitem a flexibilidade que a universidade e os professores vão precisar. Penso que quem decidir comprar um ambiente como estes deve, em paralelo, desenvolver dentro da Universidade inteligências capazes de criar o seu próprio ambiente, caso ocorra algum imprevisto durante o percurso (p. 2). 
No entanto, como destaca Alonso (2000), o importante é percebermos que o uso das tecnologias da comunicação não muda, em princípio, as questões inerentes a qualquer projeto educativo. Levando em conta que as tecnologias em si não são neutras, na medida em que elas sempre revelam uma orientação pedagógica e uma concepção de educação, percebemos que durante o desenvolvimento do Eureka estiveram presentes, mesmo que implicitamente, uma concepção teórico-metodológica específica, que tinha subjacente uma visão de aprendizagem, de homem, de trabalho e de mundo.

Sendo assim, não podemos ocultar o fato de que os ambientes virtuais constituem-se em um espaço que além de ter marcas sociais, apresentam um discurso pedagógico e científico permeado por ideologias e intenções.

Najmannovich (2001) destaca:

As tecnologias de comunicação e informação atuais oferecem meios facilitadores, mas, de forma isolada, não garantem em absoluto novas formas de ensinar, pensar e conviver. O que se tem agora é a oportunidade de desenvolver um ambiente com a possibilidade técnica de entrelaçar a cultura, a prática social, saberes, a prática pedagógica, a ciência, expressando-se por diferentes linguagens, na tentativa de produzir novos sentidos e, em conseqüência, uma nova paisagem educativa (p. 44).

Com o objetivo de facilitar e promover a comunicação entre os participantes, foram desenvolvidos inicialmente no Eureka módulos comuns aos Ambientes Virtuais utilizados até então (Info, Chat, Correio Interno, Conteúdo, Estatísticas, Fórum, Links, Participantes). Barros (2000) classifica esses módulos em 4 grupos principais: "módulo de domínio (inserção de conteúdo); módulo de apresentação (esclarecimentos gerais sobre o curso, a instituição, entre outras); módulo de convivência (ferramentas síncronas e assíncronas) e módulo de controle (acesso ao ambiente, senhas, etc.)" (p.15).

A partir do desenvolvimento de tais módulos, tanto alunos como professores e administradores dos cursos passaram a ter à sua disposição uma série de funcionalidades. No entanto, as primeiras experiências mostraram que o simples acesso a esses recursos ainda não significava muito avanço, era preciso principalmente saber como aproveitar o potencial da tecnologia.

Com a necessidade da realização de projetos e atividades de pesquisa para elucidar novas formas de ensinar e aprender, pesquisadores do Programa de Mestrado em Educação da Linha de Pesquisa de Teoria e Prática Pedagógica na Educação Superior da PUCPR desenvolveram o projeto de pesquisa denominado PACTO (Pesquisa em Aprendizagem Colaborativa com TecnOlogias Interativas). Este foi o primeiro projeto de pesquisa que incorporou o ambiente Eureka como uma ferramenta de colaboração entre professor e alunos da graduação. 
Segundo Alcântara, Behrens e Carvalho (2001), o Projeto PACTO, iniciado em outubro de 1998, tinha como objeto de pesquisa a busca por metodologias inovadoras que utilizassem a tecnologia como ferramenta para possibilitar a produção do conhecimento num paradigma emergente, levando a uma aprendizagem colaborativa baseada em projetos. A proposta era de desenvolver práticas pedagógicas enfocando o uso de tecnologias no ensino bimodal (i.e., presencial e virtual).

Do ponto de vista conceitual, foram prioritários na prática pedagógica o uso de procedimentos metodológicos que levassem à produção do conhecimento e que utilizassem os diversos recursos disponíveis na sociedade da informação, em especial, a utilização do computador, como instrumentos que auxiliassem os alunos que encontram ou não dificuldades de aprendizagem no ensino tradicional. Por ser um projeto pioneiro, a metodologia desenvolvida no PACTO serviu de referência para vários cursos ofertados na PUCPR.

Assim, a partir do desenvolvimento das ferramentas interativas do sistema e das pesquisas sobre colaboração realizadas até então, o Eureka passa a receber a denominação de Ambiente Virtual de Aprendizagem Colaborativa.

Em março de 1999, foi criada a Coordenadoria de Educação a Distância (CEAD) da PUCPR, com o objetivo de coordenar as ações de EaD da instituição, a partir das iniciativas isoladas já existentes. O Eureka naquele ano passou a ser utilizado em caráter experimental na instituição, por alguns poucos professores entusiastas. Desde então, ele tornou-se uma ferramenta de suporte aos cursos de graduação e pós-graduação. Gomes (2003) define esta experiência de virtualização universitária em 4 fases distintas, sendo o ano de 1999 o período da pesquisa.

No final de 1999 surge a Universidade Virtual Siemens PUCPR e, a partir dela, profissionais do Brasil inteiro passam a freqüentar o Eureka para cursos de treinamento profissional.

Para Peters (2003):

O conceito de ambiente de aprendizagem foi criado com base na mudança de paradigma educacional de instrução com uma finalidade voltada para metas, de bases empíricas, para aprendizagem construtivista. Os estudantes não são mais vistos como objetos, mas sim como sujeitos do processo de aprendizagem. Sua aprendizagem não consiste mais em receber e processar o conhecimento oferecido, mas em debater ativamente como um objeto de aprendizagem que eles mesmos selecionaram em um contexto que é definido a partir da interação simultânea com outros estudantes e no qual eles mesmos desenvolvem ou alteram estruturas cognitivas individuais (p. 133). 
Segundo Simão Neto (2002), por meio de uma rede colaborativa é possível buscar "(...) formas mais interativas e cooperadas, nas quais alunos e professores estão engajados em tarefas comuns, mesmo que separados espacial e em muitos casos também temporalmente". Ainda de acordo com este autor, "(...) as redes locais ou a própria Internet servem de meio para as trocas comunicativas entre os agentes da aprendizagem" (p. 61).

Entretanto, apesar do termo colaboração ter sido interpretado e utilizado de diferentes maneiras por diversos autores, em vários projetos educacionais, é importante salientarmos algumas diferenças conceituais entre colaboração e cooperação como fazem, por exemplo, Rochele e Teasley (1995):

O trabalho cooperativo é realizado através da divisão de trabalho entre os participantes, como uma atividade onde cada pessoa é responsável por uma porção da solução do problema. (...) ao passo que a colaboração envolve o empenho mútuo dos participantes em um esforço coordenado para solucionar juntos o problema (p. 11).

Collis (1993) complementa que:

A colaboração é um processo de criação compartilhada: dois ou mais indivíduos, com habilidades complementares, interagem para criar um conhecimento compartilhado que nenhum deles tinha previamente ou poderia obter por conta própria. A colaboração cria um significado compartilhado sobre um processo, um produto ou um evento (p. 13).

Desta forma, é preciso ter clareza de que um ambiente virtual de aprendizagem por si só não assegura o desenvolvimento de redes de aprendizagem colaborativa. Ele pode apenas fornecer a infra-estrutura e a arquitetura telemática necessárias ao desenvolvimento de uma comunicação multidirecional. É preciso, ainda, que tanto os alunos quanto os professores que estiverem conectados ao ambiente virtual estejam dispostos a tecer relações de troca, experimentando novas formas de ensinar e aprender.

O ano de 2000 foi destinado basicamente à criação da cultura de EaD na PUCPR. Vários cursos de graduação passaram a utilizar o Eureka como apoio ao presencial. Naquele ano, a CEAD passou a ofertar de maneira experimental alguns cursos de extensão na modalidade a distância, entre eles: web design, java e informática básica, bem como ofertou também o Curso de Especialização em Metodologias Inovadoras na Ação Docente em parceria com o Instituto Civitas e com o setor de Educação da PUCPR, para os professores dos Colégios Divina Providência.

Trabalhar com EaD numa instituição que, como a PUCPR, vem ino- 
vando nas práticas pedagógicas, como a extinção das disciplinas e departamentos estanques, requer a criação de novas diretrizes, entre as quais a capacitação contínua e permanente do corpo docente e do corpo técnico se tornam fundamentais. A PUCPR em seu Projeto Pedagógico (2000) recomenda:

a variabilidade de técnicas, procedimentos e recursos de ensino, é uma condição importante para que os professores não fiquem só na ênfase sobre os meios, com prejuízo dos processos de aprendizagem da instituição. Mais do que usar uma técnica para ensinar, os professores precisam decidir qual o melhor procedimento a utilizar (PROJETO PEDAGÓGICO - PUCPR, 2000, p. 78$)$.

Com toda a reformulação do Projeto Pedagógico da PUCPR no ano de 2000, a CEAD tentou trabalhar em sintonia com outras unidades da universidade envolvidas com a capacitação docente e com a concepção, elaboração, desenvolvimento e oferta de cursos.

Para atender à demanda de capacitação docente, a Pró-Reitoria Acadêmica criou, no ano de 2001, o Núcleo de Tecnologias Educacionais (NTE), com o objetivo de dar subsídios aos professores na utilização de tecnologias educacionais inovadoras. A ênfase do NTE tem sido a capacitação dos professores de graduação no uso pedagógico do ambiente virtual de aprendizagem EUREKA.

Segundo dados do Relatório Anual da Institucionalização do Ambiente Virtual de Aprendizagem Eureka do ano de 2001, havia mais de 500 salas virtuais abertas, e mais de 10.000 pessoas cadastradas no sistema. No entanto, ainda de acordo com a análise realizada, verificou-se que apesar do grande número de salas abertas, apenas 18 delas puderam ser classificadas na categoria "exemplares" .

Estes dados nos mostram que foram poucos os professores que conseguiram, por meio de ações inovadoras, explorar todo o potencial de interação do sistema.

Segundo Simão Neto (2003):

Esta análise inicial nos leva a pensar que a disponibilização de um novo meio não linear e interativo não leva necessariamente a uma nova forma de ensinar e aprender. Pode ser facilmente domesticado e colocado a serviço de propostas pedagógicas centradas na transmissão/assimilação acrítica de conteúdos (p. 150).

4 De acordo com o Relatório Técnico, as salas classificadas como exemplares eram aquelas que tinham um número de editais acima de 10 inclusive, (ou) número de inserções no fórum acima de 11 inclusive, (e) número de links acima de 10 inclusive, (e) número de participantes acima de 15 . 
É importante salientarmos que os ambientes virtuais de aprendizagem, por mais que ofereçam ferramentas interativas, não irão conseguir sozinhos que os alunos aprendam a construir seus conhecimentos colaborativamente. É preciso principalmente que os professores sejam orientados nesta nova rota e que estejam dispostos a experimentarem novas formas de ensinar e aprender.

Segundo Hesketh (2003):

Ainda que a aprendizagem colaborativa possa acontecer sem a presença da tecnologia, acreditamos que esta pode ampliar e potencializar a aprendizagem e a construção de conhecimento desde que as pessoas envolvidas sejam comprometidas com novas formas de ensinar e aprender (p. 123).

E nesta perspectiva Moran (2000) enfatiza que:

Estamos numa fase de transição na educação a distância. Muitas organizações estão se limitando a transpor para o virtual adaptações do ensino presencial (aula multiplicada ou disponibilizada). Há um predomínio de interação virtual fria (formulários, rotinas, provas, e-mail) e alguma interação on-line (pessoas conectadas ao mesmo tempo, em lugares diferentes). Apesar disso, já é perceptível que começamos a passar dos modelos predominantemente individuais para os grupais na educação a distância. Das mídias unidirecionais, como o jornal, a televisão e o rádio, caminhamos para mídias mais interativas e mesmo os meios de comunicação tradicionais buscam novas formas de interação. Da comunicação off-line estamos evoluindo para um mix de comunicação off e on-line (em tempo real). (p. 1)

Temos percebido que uma das grandes dificuldades por que passou a EaD da PUCPR foi ter introduzido tecnologias avançadas, num período em que os professores enfrentavam os primeiros problemas relacionados às mudanças dos modelos pedagógicos incorporados nas práticas.

Segundo Peters (2003):

A educação a distância tradicional provavelmente em breve estará fora de moda, e terá que se reorientar e desenvolver novas estruturas pedagógicas. A aprendizagem independente e auto-regulada, assim como a aprendizagem em grupo, se tornará importante. Cursos pré-fabricados para grandes números de estudantes irão, no entanto, perder sua importância corrente, assim como o método expositivo de ensinar, que está ligado a um modo receptivo de aprender (p. 56).

Como vimos até agora, nestes quatro anos de caminhada, as ações realizadas pela Coordenadoria de Educação a Distância na PUCPR aconteceram de forma isolada. 
Até 2002 não havia sido possível a elaboração de um plano de EaD para a instituição. No entanto, a partir desta época, tornou-se fundamental a elaboração de um plano estratégico para o futuro.

Vale ressaltar que o ano de 2002 foi decisivo para a Educação a Distância da PUCPR. Após discussões contínuas com as Pró-Reitorias e diretorias de centro, o plano foi elaborado e apresentado ao Conselho Universitário (CONSUN) - passando a EaD a fazer parte dos principais objetivos estratégicos da instituição.

Em função deste avanço, a administração passou a investir com maior ênfase no setor. A equipe que até então funcionava com 3 professores e alguns estagiários foi sendo aumentada, passando a ser constituída por três núcleos principais: Pedagógico, de Comunicação e Tecnológico.

Segundo o projeto de EaD da PUCPR, o Núcleo Pedagógico passa a ser responsável pelas atividades de formação de docentes e gestores para atuarem na $\mathrm{EaD}$ e no assessoramento e desenvolvimento de metodologias específicas para os cursos e atividades a distância, bem como pelo acompanhamento e avaliação destes cursos no que diz respeito às questões estruturais.

O Núcleo de Comunicação passa a ter como responsabilidade principal a definição e concepção dos produtos de mídia a serem usados nos cursos a distância, em consonância com as definições do núcleo pedagógico.

E o Núcleo Tecnológico torna-se responsável pelas atividades de estruturação, atualização e manutenção da infra-estrutura tecnológica da EaD, incluindo os equipamentos e instalações de videoconferência e ambiente virtual de aprendizagem Eureka.

Ainda em 2002 a PUCPR adotou como política de desenvolvimento da EAD na instituição a estruturação de um sistema de comunicação interligando os diversos campi (i.e., Londrina, Toledo, São José dos Pinhais e Curitiba) e unidades, por meio de sistema de videoconferência, da Internet, criando uma rede virtual para geração e distribuição dos cursos e atividades tanto a distância como presenciais, apoiadas pelas tecnologias e meios comunicativos.

Tal projeto diz respeito ao que Peters (2003) denominou de modelo de educação a distância baseado na rede. Para o autor, este modelo está surgindo como parte da transformação digital do modo como trabalhamos e vivemos e comenta que:

A maior vantagem pedagógica, no entanto, é que os alunos são desafiados a desenvolverem novas formas de aprendizagem, buscando, encontrando, adquirindo, avaliando, julgando, modificando, armazenando e recuperando 
informação quando necessário. Têm a chance de aprender fazendo suas próprias descobertas e serem introduzidos à aprendizagem fazendo pesquisa (p. 80).

Este modelo é certamente complexo e exigente. Mas é promissor porque disponibiliza novas dimensões de empenho pedagógico na educação a distância.

As estruturas técnicas de rede permitem a implementação de formas novas e mais complexas de interação social, fazendo emergir a possibilidade da troca imediata no ciberespaço. Neste contexto da aprendizagem em rede, percebemos que a interatividade passa a ser uma das palavras chaves.

Para Silva (2000), as novas tecnologias interativas renovam a relação do usuário com a imagem, com o texto, com o conhecimento. São de fato um novo modo de produção do espaço visual e temporal mediado. Elas permitem o redimensionamento da mensagem, da emissão e da recepção. Segundo o autor:

Um produto, uma comunicação, um equipamento, uma obra de arte, são de fato interativos quando estão imbuídos de uma concepção que contemple complexidade, multiplicidade, não linearidade, bidirecionalidade, potencialidade, permutabilidade (combinatória), imprevisibilidade, etc., permitindo ao usuáriointerlocutor-fruidor a liberdade de participação, de intervenção, de criação (p. 100).

Neste contexto, o projeto do Campus Virtual, por explorar o uso das tecnologias interativas, permite a participação, a intervenção, a bidirecionalidade e a multiplicidade de conexões, estabelecendo relações dialogais e criativas para o enriquecimento da aprendizagem. Este se tornou um dos grandes diferenciais competitivos da universidade, dificilmente superado por outras instituições no Estado do Paraná.

A partir de 2002, começaram a ser realizados os primeiros seminários e palestras, compartilhadas no espaço virtual.

Já em 2003 a estrutura de videoconferência do Campus Virtual passou a ser utilizada com maior ênfase na instituição pelos diversos setores (i.e., palestras dialogadas, aulas complementares, cirurgias, apresentações de trabalhos, reuniões administrativas), bem como a equipe de desenvolvimento do EUREKA passou a fazer parte oficialmente da CEAD.

Segundo o Projeto de Credenciamento de Programas de Pós-Graduação Lato Sensu na modalidade a distância da Pontifícia Universidade Católica do Paraná (2004), dentro do conceito do Campus Virtual define-se o modelo de EAD da PUCPR, no qual os alunos não são indivíduos isolados em suas localidades distantes, mas fazem parte de comunidades locais de aprendizagem. Em cada localidade, o grupo de alunos é acompanhado por um professor-assistente responsável pela organização local e pelo acompanhamento das atividades de aprendizagem. 
Este modelo visa a promover a interação dos alunos e facilitar a realização das atividades de videoconferência, bem como viabilizar a realização das avaliações presenciais em cada localidade.

No modelo de EAD da PUCPR, as comunidades locais de aprendizagem interagem entre si e com o professor nos momentos telepresenciais e virtuais.

Segundo Kleinschroth, apud Peters (2003), "o fenômeno da telepresença é uma característica espacial importante. Isso reduz drasticamente a distância entre estudantes e professores, e entre os próprios estudantes, e permite "presença mental com ausência física" (p. 143).

Ainda de acordo com o modelo de EaD utilizado pela universidades, os momentos telepresenciais visam a promover a interação em tempo real entre o professor e os alunos, sendo realizados por meio de sessões de videoconferência. Pretende-se, com isso, oferecer momentos com alto grau de interatividade na comunicação professor-aluno e garantir a sincronização entre os grupos de estudo.

Já nos momentos virtuais, os alunos desenvolvem, individualmente ou em grupos, as atividades de aprendizagem propostas, como, por exemplo, leituras e sínteses, discussões de grupo (síncronas e assíncronas), pesquisas dirigidas, elaboração de trabalhos, etc. Para a realização destas atividades, os alunos dispõem do ambiente Eureka, os quais serão também acompanhados pelo professor-assistente.

Estando o modelo de EaD da PUCPR em vias de consolidação, será preciso concretizá-lo mais amplamente na prática. Portanto, a oferta de cursos na modalidade dual ou a distância, tornou-se fundamental. O convênio com a DTCOM (Direct to Company S/A), firmado no final de 2003 foi o passo seguinte para a formatação de um MBA in Company, na área de Gestão de Negócios, usando a infra-estrutura de comunicação via satélite da empresa.

O projeto deste curso foi encaminhado ao MEC, juntamente com o Projeto de credenciamento de Programas de Pós-graduação Lato Sensu, na modalidade a distância. O ano de 2003 terminou com o início da formatação dos primeiros módulos.

\section{Um salto para o Presente}

"A performance de hoje é o produto do aprendizado do passado. A performance de amanhã é um produto do aprendizado de hoje". (GUNS, 1996, p. 14)

Desde a sua criação em 1999 até os dias atuais, a Coordenadoria de Educação a Distância da PUCPR passou por três coordenadores diferentes. Cada um dos professores envolvidos na gestão do setor trouxe sua experiência oriunda de sua formação acadêmica específica, contribuindo para a CEAD tornar-se o que é hoje. 
Para a instituição desenvolver seletivamente a educação a distância, foram identificadas áreas estratégicas de atuação, entre elas destaca-se inicialmente a Extensão e a pós-graduação em nível de Lato Sensu. Entretanto, se considerarmos que no Brasil, segundo Vianney, Torres \& Silva (2003), até o final do ano de 2002 apenas 24 universidades estavam oficialmente credenciadas pelo MEC para ofertar cursos Lato Sensu na modalidade a distância, percebemos que este é um processo moroso, o qual depende de inúmeros fatores para funcionamento adequado.

Ainda no primeiro semestre deste ano, está prevista também a implantação do Programa, PUCweb, visando a ampliar a área de atuação da instituição, com a oferta de cursos de extensão na modalidade a distância. Mantendo a tradição e a qualidade que a PUCPR sempre buscou oferecer à comunidade, este programa procurará atender estudantes e profissionais que têm procurado uma formação continuada.

Com uma metodologia própria e cada vez mais em sintonia com o projeto pedagógico da instituição, os cursos da PUCweb serão ofertados totalmente a distância, sendo o EUREKA o principal recurso tecnológico utilizado. De acordo com o Projeto Pedagógico da PUCPR (2000):

O conhecimento do passado precisa constituir uma efetiva base para inventar o futuro. E isso pode ser feito por meio da capacidade de construir, derivando do melhor conhecimento existente, as aptidões que devem constituir a aprendizagem dos que viverão no futuro, e serão os principais agentes para definir e construir esse futuro (p. 24-25).

Com uma equipe multidisciplinar afinada, disposta a realizar um trabalho diferenciado com os professores no que se refere à formatação dos cursos online, com um ambiente virtual sendo constantemente aprimorado para atender as especificidades da EaD e contando ainda com o aval da instituição, podemos dizer que a concretização das metas futuras da PUCPR estão cada vez mais próximas do presente.

\section{De volta para o Futuro}

"Quando o futuro vira passado, é fácil ver o que tinha que ser feito". (AUTORANÔNIMO)

Após termos acompanhado a trajetória da EaD da PUCPR em consolidação, percebemos que foi aprendendo com as experiências do passado que pudemos melhorar o presente e conseqüentemente visionarmos o futuro. Quando tentamos imaginar a estrutura pedagógica da educação a distância da PUCPR daqui a alguns anos, podemos pensar numa instituição muito mais flexível, em 
que os alunos possam ampliar as possibilidades de escolhas, seja quanto ao espaço (onde estudar), ao tempo (quando estudar) ou quanto ao ritmo (em que velocidade aprender).

Para Peters (2003), a universidade virtual do futuro deve combinar os elementos mais bem-sucedidos da educação a distância, os elementos mais promissores da aprendizagem baseada na rede e a alegria e o imenso benefício do debate acadêmico com eruditos altamente competentes, face a face no campus.

A PUCPR, neste contexto, inovaria e reformaria consideravelmente a educação superior, estando apta para os desafios educacionais da sociedade do conhecimento pós-industrial.

O ensino e a aprendizagem na universidade devem ser orientados, muito mais do que antes, para os princípios da educação continuada e da educação permanente. Ter um caráter igualitário e ser aberta, assim como ser orientada para o estudante, para a prática e para o futuro. Terá que seguir com programas flexíveis de ensino e aprendizagem que proporcionem não apenas competência cognitiva, como também competência comunicativa e de trabalhar em colaboração (PETERS, 2003).

Sendo a Visão de Futuro da PUCPR no horizonte de 2010 uma descrição (ou imagem) da situação desejada para a instituição num longo prazo, esta representa uma meta concreta e alcançável, tendo em vista que serão priorizados três grandes rumos: a qualidade, a inovação, o crescimento.

De acordo com o Plano Estratégico da instituição, o diferencial da PUCPR consistirá: na qualificação do aluno e na sua formação com ênfase na sua empregabilidade; na qualificação do seu corpo docente; na elaboração e implantação de projetos pedagógicos consistentes; na implantação e manutenção de uma infra-estrutura de excelência; na profissionalização da sua gestão; na ampliação da flexibilidade acadêmica; na utilização de novas metodologias de ensino e de recursos tecnológicos no processo ensino/aprendizagem; bem como na atuação no ensino a distância, na atuação na educação continuada; na utilização de novos processos de seleção dos alunos de graduação; na inovação na gestão mediante a realização de parcerias e da busca de novas formas de financiamento das atividades da Universidade; na expansão programada do número de alunos; na oferta de cursos de grande potencial para o sistema produtivo; na otimização do uso da base física instalada; na presença da Universidade no Litoral do Estado do Paraná, na flexibilidade e agilidade para aproveitar as oportunidades emergentes; na abertura de cursos de Pós-Graduação, Lato e Stricto Sensu.

Desta forma, até o ano 2010, a Pontifícia Universidade Católica do Paraná será reconhecida como uma universidade de referência nacional, pelo dinamismo, pela criatividade e qualidade de seus cursos e pelos serviços prestados à comunidade, tornando-se ainda um pólo relevante de educação a distância. 
Peters (2003) comenta que:

A universidade do futuro usará e integrará uma grande quantidade de formas de apresentação, face a face, a distância e informatizada, e irá assim desenvolver novas configurações pedagógicas que não se parecerão mais com as formas tradicionais de ensino. Esta universidade estará aberta para adultos mais jovens assim como para adultos mais velhos que serão capazes de começar, interromper, continuar e terminar seus estudos quando lhes for conveniente. Não terão que estar presentes, nestas universidades o tempo todo, talvez apenas pôr períodos mais curtos (p. 65).

Esta visão da universidade do futuro indica como realmente são importantes as mudanças de paradigma educacional. Os professores devem não apenas compreender esta mudança fundamental, como também a necessidade de se tornaram agentes ativos dela.

De acordo do o Estudo Delphi-II (Bundersministerium, 1998) apud Peters (2003), que foi organizado e publicado pelo Ministério Federal de Educação e Ciência da Alemanha, as seguintes mudanças acontecerão no período até cerca de 2020:

- a partir de 2005, o sistema de educação a distância será usado em geral para o treinamento suplementar da população;

- a partir de 2007, a educação levará cada vez mais a pacotes de qualificações individuais e não a graus ou diplomas;

- a partir de 2008, medidas suplementares para o treinamento dos trabalhadores estarão totalmente integradas no horário de trabalho;

- a partir de 2010, universidades virtuais globais estarão disseminadas (p. 91).

Por mais que essas quatro profecias não cheguem a ocorrer exatamente desta forma,

mesmo que apenas algumas delas se realizem, uma ocorrência é certa: elas nos chamam atenção eficazmente para as mudanças necessárias e iminentes.

É claro que ninguém sabe o futuro, em particular porque ele pode ser construído e também determinado por fatores hoje desconhecidos. No entanto, neste cenário de prognósticos e incertezas, podemos dizer que o futuro da Educação a Distância da PUCPR já começou. Como nos diz Prigogine (1996): o tempo é construção. Não podemos ter a esperança de predizer o futuro, mas podemos influir nele (p. 39). 


\section{Referências}

alcântara, P.R.; BeHrens, M.A; CARVAlHO, R.G. Projeto PACTO: Pesquisa em Aprendizagem Colaborativa com Tecnologias Interativas (1999-2000). Pontifícia Universidade Católica do Paraná.Curitiba. CD-ROM, 2001.

ALONSO, K. Novas tecnologias e formação de professores. In: PRETTI, O. Educação a distância: construindo significados. Cuiabá: NEAD/IE; UFMT, 2000.

BARROS, A. N. Uma arquitetura consensual para ambientes virtuais de estudo. In: PROJETO VIRTUS: educação e interdisciplinaridade no ciberespaço. Recife: Anhembi Morumbi - Universitária UFPE, 2000.

CARNEIRO, M.L.F. Videoconferência: ambiente para apoio à educação a distância. Porto Alegre: UFRGS, 2000.

COLLIS, B. Cooperative Learning and CSCW: research perspectives for Internet worked educational environments. IFIP Working Group 3.3 Working Conference "Lessons from Learning". France: Archamps, Sept, 1993.

PONTIFÍCIA UNIVERSIDADE CATÓLICA DO PARANÁ. Diretrizes para o ensino de graduação: o projeto pedagógico da PUCPR. Curitiba: Champagnat, 2000.

GOMES P.V; MATOS E.L.M; Uma experiência de virtualização universitária: o eureka da PUCPR. Curitiba: Champagnat, 2003.

GOMES, P.V.; VERMELHO, S.C., HESKETH, C.; SILVA, A.C. Relatório Técnico de Avaliação do Ambiente Eureka na PUCPR. Curitiba, 2001.

GUNS, B. The Faster Learning Organization. Jossey-Bass, 1996.

HESKETH, C. G. Problematizando situações, compartilhando soluções: o caso da FEMPAR. In: MATOS E.L.M.; GOMES P.V. Uma experiência de virtualização universitária: o Eureka da PUCPR. Curitiba: Champagnat, 2003.

LUCENA, C.J.P; FUKS, H; LAUFER, C. Videoconferência em Web-Based Learning. Disponível em: http://wwwedit.inf.ufsc.br:1998/materiais/sbie98/anais/artigos/ art18.html. Acesso em 5 Dez. 2003.

McLUHAN, M. Os Meios de Comunicação como Ex tensão do Homem. São Paulo, SP. Cultrix, 1996.

MORAN, J. M. O que é educação a distância? Disponível em: http:// www.virtual.nuca.ie.ufrj.br/infoeducar/artigos/moran2.htm. Acesso em 10 Jan. 2004. NAJMANOVICH, D. O sujeito encarnado: questões para a pesquisa no/do cotidiano. Rio de Janeiro, RJ: DP\&A, 2001. 
PETERS, O. A educação a distância em transição. São Leopoldo: Unisinos, 2003.

PERNIAS P. P. Entrevista exclusiva para Colabora. Revista Digital daCVA-RICESU, v.1, n.4, Maio 2002. Disponível em http://gemini.ricesu.com.br/colabora/n4/ index1.htm. Acesso em 10 Jan. 2004.

PONTIFÍCIA Universidade Católica do Paraná. Plano Estratégico. Período 20022006. Curitiba: Champagnat, 2002.

PRIMO, A.F.T. Seria a multimídia de fato interativa? Revista da Famecos, Porto Alegre, n.6, 1997.

Ferramentas de Interação na web: travestindo o ensino tradicional ou potencializando a educação através da cooperação? Disponível em: <http:usr.psico.ufrgs.br/ aprimo/ead/tools.htm>. Acesso em 29 Mar. 2004.

PRIGOGINE, I. Dos relógios às nuvens. IN: SCHNITMAN, D. Novos paradigmas, cultura e subjetividade. Porto Alegre: Artes Médicas, 1996.

PROJETO DE CREDENCIAMENTO DE PROGRAMAS DE PÓS-GRADUAÇÃO LATO-SENSU NA MODALIDADE A DISTÂNCIA. Pontifícia Universidade Católica do Paraná. 2004.

QUINTANA, M. Os melhores poemas. São Paulo, SP: Global, 1983.

ROSCHELLE, J; TEASLEY, S. The Construction of Shared Knowledge in Collaborative Problem Solving. In C. E. O Malley (Ed.) Computer Supported Collaborative Learning. Berlim: Springer-Verlag, 1995.

SANTOS, M. O lugar e o cotidiano. Disponível em: http:www.gilbertogil.com.br/ santos/texto.htm. Acesso em 10 nov. 2003.

SIMÃO, A. N. Uma tipologia das formas de educação a distância com base nas mídias utilizadas e no grau de interação entre os agentes. Colabora - Revista Digital da CVA-RICESU. v.1, n. 4, Maio de 2002.

Comunicação e interação em ambientes de aprendizagem presenciais e virtuais. In: MATOS, E.L.M.; GOMES, P.V. Uma experiência de virtualização universitária: o eureka da PUCPR. Curitiba: Champagnat, 2003.

VIANNEY, J; TORRES, P.; SILVA. E. A Universidade Virtual no Brasil. Tubarão: Unisul, 2003. 